\title{
Estudo da ação da romã (Punica granatum L.) na cicatrização de úlceras induzidas por queimadura em dorso de língua de ratos Wistar (Rattus norvegicus)
}

\author{
NASCIMENTO JÚNIOR, B.J. ${ }^{*} ;$ SANTOS, A.M.T.'; SOUZA, A.T.'; SANTOS, E.O.1; XAVIER, M.R. '; MENDES, \\ R.L.'; AMORIM, E.L.C. ${ }^{2}$ \\ Universidade Federal do Vale do São Francisco - UNIVASF. Av. José de Sá Maniçoba, S/N - Centro, CEP:

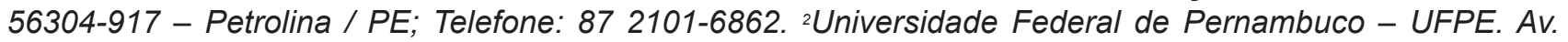 \\ Prof. Moraes Rego, 1235 - Cidade Universitária, Recife - PE - CEP: 50670-901. *Autor para correspondência: \\ braznjunior@gmail.com
}

RESUMO: O objetivo desse estudo foi observar a ação da romã (Punica granatum L.) em estomatites induzidas por queimaduras no dorso da língua de ratos Wistar. Foram utilizados 24 ratos Wistar machos adultos, provenientes do Biotério da UNIVASF. Foram formados quatro grupos (G1: Polpa da romã por gavagem; G2: Polpa da romã por gavagem + aplicação local do chá da casca do fruto; G3: aplicação local do chá da casca do fruto e G4: Controle negativo). As queimaduras foram confeccionadas com instrumental odontológico padrão. Os tratamentos foram realizados duas vezes ao dia, durante 14 dias. Metade dos animais de cada grupo $(n=3)$ foi eutanasiada no sétimo dia de experimentação, enquanto o restante foi eutanasiado no $14^{\circ} \mathrm{dia}$. As línguas foram removidas e fixadas com formaldeído a $10 \%$ tamponado, processadas com cortes de $5 \mu \mathrm{m}$ e coradas em HE. Clinicamente, os animais do grupo $\mathrm{G} 2$ tiveram melhores resultados. $\mathrm{Na}$ análise histológica qualitativa foi avaliada a reepitelização e os graus de inflamação numa escala de 0 a 4. Na análise estatística, utilizou-se o teste Qui-quadrado de Pearson. Houve significância estatística $(p=0,026$ e $p=0,023)$ quando se comparou o tratamento com os graus de reepitelização e inflamação nos quatro grupos estudados. O grupo G2 apresentou cicatrização completa com 14 dias. Os piores escores obtidos foram atribuídos ao Grupo G4 nos dois parâmetros de avaliação qualitativa. Diante dos resultados obtidos, observa-se que a romã (Punica granatum L.) possui ação cicatrizante na mucosa lingual de ratos Wistar.

Palavras Chave: Punica granatum L., cicatrização, estomatites.

\begin{abstract}
Pomegranate action study (Punica granatum L.) for the healing of ulcers induced by burns to the dorso-lingual mucosa in Wistar rats (Rattus norvegicus). The objective of this study was to observe the action of pomegranate (Punica granatum L.) on stomatitis induced burns on the dorso-lingual musosa in Wistar rats. Twenty-four male, adult Wister albino rats were used, from the bioterium of UNIVASF. There were four groups (G1: Pomegranate juice by gavage; G2: Pomegranate juice by gavage + local application of fruit peel tea; G3: Local application of fruit peel tea only and G4: a negative control). The burns were made with standard dental instruments. The treatments were performed twice a day for 14 days. Half the animals in each group $(n=3)$ were euthanized on the seventh day of experimentation, while the remainder were euthanized on day 14 . The tongues were removed and fixed with a $10 \%$ formaldehyde buffer, processed as $5 \mu \mathrm{m}$ sections and stained with HE. Clinically the animals treated with tea showed better healing. For statistical analysis the Pearson chi-squared test was used. There was a statistical significance $(p=0.026$ and $p=0.023)$ when compared to treatment with the degree of re-epithelialization and inflammation of the four groups studied. The G2 group showed complete healing within 14 days. The worst scores were found in the G4 group in both qualitative assessment parameters. Based on these results, it was observed that pomegranate (Punica granatum L.) has a healing action on the lingual mucosa of Wistar rats.
\end{abstract}

Keywords: Punica granatum L., wound healing, stomatitis. 


\section{INTRODUÇÃO}

O Brasil é um país que possui grande número de espécies vegetais com propriedades medicinais e que são usadas pela população há muito tempo, como no caso da romã (Punica granatum L.). Os preparos obtidos da romãzeira (flor, fruto e casca do fruto) são popularmente usados para tratar vários problemas de saúde tais como faringites, laringites, bronquites, lesões e abscessos de pele e mucosas, diarreias de origem bacteriana e parasitária, cólicas, hemorroidas, infecções de vias urinárias e genitais, viroses em geral, infecções por fungos, conjuntivites, gengivites, glossites, e estomatites aftosas ou aftas (Holetz et al., 2002; Rodrigues et al., 2006; Oliveira et al., 2010).

A polpa da romã é usada para tratar úlceras na boca e genitálias, apresenta compostos fenólicos como: antocianinas (delfinidina, cianidina e pelargonidina), quercetina, ácidos fenólicos (caféico, catequínico, clorogênico, orto e paracumárico, elágico, gálico e quínico) e taninos (punicalagina) (Noda et al., 2002; Seeram et al., 2005). É bem conhecida por possuir excelente atividade antioxidante, antiteratogênica, antiproliferativa e anti-inflamatória, por conter compostos bioativos que são poderosos antioxidantes, particularmente os polifenóis. As a punicalaginas e monômeros $\beta$ são os elagitaninos responsáveis pelas propriedades do suco de romã (Faria \& Calhau, 2011). A casca do fruto também possui atividade antioxidante, rica em flavonoides e taninos (Moneim, 2012). Dentre os fitoconstituintes presentes na planta, destacam-se flavonóides (apigenina e narigenina), antocianinas, taninos (ácidos gálico e elágico), alcalóides, ácido ascórbico, ácidos graxos conjugados (ácido púnico) e o ácido ursólico (Lansky \& Newmann, 2007).

De acordo com a medicina popular, o gargarejo da decocção das cascas do fruto é usado para tratar problemas de faringite e laringite. O uso etnofarmacológico da fruta, que é nativa da região do Oriente Médio, está principalmente associado a sua ação antioxidante e antiinflamatória. (Ross et al., 2001, Jardini \& Mancini filho, 2007). Estudos científicos têm ampliado o leque dos efeitos dessa punicácea, atribuindo-lhe importantes propriedades fisiológicas como anticancerígena (Afaq et al, 2005), bactericida tópica (Neurath et al, 2004), cardioprotetora (Sumner et al., 2005), melhora nos parâmetros bioquímicos (Rodrigues et al, 2006), tratamento de úlceras bucais, por suas características antioxidante, imunomoduladora e bactericida (Ajaikumar et al., 2005).

As principais úlceras bucais são as aftas, que são pequenas úlceras, redondas ou ovais, cercadas por halo indolor, eritematoso e superficial. Essas afecções possuem diversas causas, no entanto, nenhuma estabelecida de forma precisa.
Por a etiologia ainda ser desconhecida, não há tratamento estabelecido para a cura das lesões até o momento. Elas podem estar localizadas em todas as áreas da cavidade oral, incluindo a mucosa labial, vestibular, assoalho da boca e língua. A duração das lesões é de 10 a 14 dias e as recorrências podem variar, mas geralmente aparecem a cada 2 a 3 meses. Este tipo úlcera bucal tem processo cicatricial mais lento por estar associado com a presença de infiltrado linfocitário intenso (Regezi, 2003).

Todas as formas de tratamento são voltadas para o alívio dos sintomas e cicatrização das úlceras. Os medicamentos usados reduzem a dor e a frequência de aparecimento das lesões. Esses tratamentos podem ser administrados de forma tópica ou sistêmica, através do uso de medicamentos alopáticos, homeopáticos ou produtos naturais, além das formas alternativas de tratamento como a aplicação do laser de baixa potência (Hello et al., 2010; Messadi \& Younai, 2010; Costa \& Castro, 2013).

Esse artigo teve o objetivo de observar a influência da ingestão da polpa e da ação local da decocção da casca do fruto da romãzeira (Punica granatum L.) na cicatrização de úlceras induzidas por queimaduras em dorso de língua em ratos Wistar (Rattus norvegicus).

\section{MATERIAL E MÉTODOS}

\section{Coleta do material vegetal}

Os frutos frescos foram colhidos em Casa Nova-Bahia-Brasil, identificados por moradores do local e confirmados pelos autores do artigo, realizado o registro fotográfico e o georreferenciamento, através do Sistema de Posicionamento Global (GPS) (Latitude: 09 10' 43" S; Longitude: 40 50' 15" W; Altitude de $390 \mathrm{~m}$ ). As exsicatas foram depositadas no HVASF - Herbário da Universidade do Vale do São Francisco.

\section{Preparo do suco da polpa e do chá das cascas dos frutos de $P$. granatum}

Inicialmente os frutos foram lavados, secos, em seguida abertos, tendo a polpa separada das sementes do fruto. O suco concentrado obtido foi coado, liofilizado e guardado sob congelamento $\left(-20^{\circ}\right.$ C). As cascas das romãs foram separadas e secas em estufa a $33^{\circ} \mathrm{C}$ durante sete dias, em seguida moídas em um moedor elétrico e armazenadas em sacos de plástico e mantidas a $7^{\circ} \mathrm{C}$ até o momento das aplicações.

O suco da polpa de romã foi administrado por gavagem, duas vezes ao dia, na dosagem de 
$300 \mathrm{mg} / \mathrm{Kg}$ (Mohan et al., 2010). O chá foi preparado por decocção com $5 \mathrm{~g}$ do pó em $10 \mathrm{ml}$ de água destilada, fervido por 1 minuto (Teles \& Costa, 2014). Coava-se, deixava-se esfriar e com uma seringa Luer, aplicava-se de 0,5 a 0,6 $\mathrm{ml}(1 \mathrm{~g} / \mathrm{Kg})$ sob a queimadura duas vezes ao dia, na intenção de simular um bochecho (Figura 1B).

\section{Caracterização química das amostras}

$\mathrm{Na}$ análise química da polpa, encontrou-se os seguintes metabólitos secundários: Antocianinas (Cianidina 3,5-diglicosídeo), Flavanóides (quercetina), Ácidos Fenólicos (Ácido Caféico) e Taninos. As cascas dos frutos apresentaram os seguintes fitocomplexos: Flavonóides, Ácido Elágico e Punicalagina. A determinação química foi realizada por cromatografia de coluna segundo a técnica usada por Luque-Rodriguez et al. (2007).

\section{Avaliação da atividade cicatrizante in vivo Animais}

Foram utilizados 24 ratos machos (Rattus norvegicus, linhagem Wistar, variação albinus), com idades entre 60 e 65 dias e com pesos entre $250 \mathrm{~g}$ e $300 \mathrm{~g}$, provenientes do Biotério Central da UNIVASF. Eles ficaram em sala fechada e isolada, com umidade de $55 \%$, temperatura de $22 \pm 2{ }^{\circ} \mathrm{C}$, controlada por ar-condicionado, iluminação por período de 12 horas, seguida por 12 horas de escuridão. Esses animais também receberam água e ração comercial à vontade. Durante os 14 dias de experimentação, os animais foram divididos em oito gaiolas metálicas, contendo em cada uma, três ratos. Outros quatro animais foram usados num estudo piloto realizado previamente, porém não entraram nos resultados finais, serviram para ajuste da técnica.

\section{Desenho experimental}

Os grupos foram: G1: Seis ratos (polpa da romã por gavagem, duas vezes ao dia); G2: Seis ratos (polpa de romã, por gavagem, duas vezes ao dia + decocção da casca desidratada do fruto, aplicada sobre as lesões, duas vezes ao dia); G3: Seis ratos (decocção da casca desidratada do fruto, aplicada sobre as lesões, duas vezes ao dia; G4: Controle Negativo com seis ratos (água destilada dada por gavagem + água destilada administrada sobre as lesões).

No início do experimento os animais foram pesados e anestesiados por via intraperitoneal, com associação anestésica de cetamina e xilazina para uso veterinário, na dose de $60 \mathrm{mg} / \mathrm{Kg}$ e $10 \mathrm{mg} / \mathrm{Kg}$ de peso corporal, respectivamente. A ação anestésica foi verificada pela ausência do reflexo de retirada da pata ao estímulo doloroso.

Após a anestesia geral, procederam-se as queimaduras na parte posterior do dorso da língua dos animais (Figura 1A). O instrumental utilizado nas lesões foi de uso odontológico, denominado de condensador de amálgama número 2 que possui um diâmetro $3 \mathrm{~mm}$ (área $=7,065 \mathrm{~mm}^{2}$ ). Esse era levado ao aquecimento (cor rubra) em um bico de Bunsen e encostado na mucosa lingual dos animais por 1 segundo. Em seguida, esperou-se a recuperação anestésica e já se procederam às administrações dos derivados de romã de acordo com os grupos pré-estabelecidos. Foi administrado na água do bebedouro, acetominofenol na dosagem de $1 \mathrm{mg} /$ $\mathrm{ml}$ por 24 horas.

\section{Análise dos resultados}

A avaliação clínica foi realizada após o aprofundamento anestésico, antes da eutanásia. As línguas foram tracionadas pelo ápice e em seguida fotografadas a uma distância de $30 \mathrm{~cm}$, utilizandose uma câmara digital (Nikon Coolpix L120, Japão).

Para os estudos histológicos, três ratos de cada grupo sofreram eutanásia aos sete e 14 dias de experimento, e em seguida, toda a língua do animal era removida nas amostras (Figura 1C). Estas amostras de tecido foram mantidas em solução de formalina a $10 \%$ tamponada por $48 \mathrm{~h}$ e enviadas para o laboratório patologia da Universidade Federal de Pernambuco para a confecção das lâminas. Após lavagem com água, os espécimes foram desidratados e embebidos em parafina, cortados no sentido transversal em seções de $5 \mathrm{~mm}$, coradas com Hematoxilina e Eosina (HE). Foi obtida uma lâmina de cada animal. Foram observadas nas lâminas coradas, a reepitelização, as alterações inflamatórias, células polimorfonucleares e fibroblastos. Todas as lâminas foram observadas em microscópio de luz com magnitude de Ampliação de 10X (Olympus, Japão), com câmera acoplada Celestron ${ }^{\circledR}$ Digital Microscope Imager modelo 44421 (Torrance, Califórnia, Estados Unidos), usando programa fornecido pela própria câmera digital.

A análise descritiva e as avaliações dos grupos foram realizadas em duplo cego, por patologista e por cirurgião dentista especialista para uma pontuação final consensual. O grau de reepitelização foi determinado um sistema de classificação (0 a 4), ou seja, Grau 0: Reepitelização na borda da ferida; Grau 1: Reepitelização cobrindo menos da metade da ferida; Grau 2: Reepitelização cobrindo mais da metade da ferida; Grau 3: Reepitelização cobrindo toda a ferida, porém com espessura irregular e Grau 4: Reepitelização cobrindo toda a ferida e com espessura normal, como descrito por outros autores (Sinha \& Gallagher, 2003). O grau de inflamação também foi avaliado de acordo com um sistema de classificação (1 a 4), tal

Rev. Bras. PI. Med., Campinas, v.18, n.2, p.423-432, 2016. 
como descrito por Camacho-Alonso \& Lopez-Jornet (2007), ou seja, Grau 1: Inflamação aguda; Grau 2: Predominância difusa de inflamação aguda; Grau 3: Predominância de inflamação crônica e Grau 4: Resolução e Cicatrização.

$\mathrm{Na}$ análise estatística foi realizado um estudo descritivo de cada variável. As associações entre as diferentes variáveis foram estudadas por meio do teste do qui-quadrado de Pearson com nível de significância $\leq 0,05$. Os resultados foram expressos como médias.

\section{Critérios éticos da pesquisa}

Essa pesquisa foi resultante de um projeto de iniciação científica, realizado dentro das Normas Internacionais de Proteção aos Animais, da Diretriz Brasileira para o cuidado e a utilização de animais para fins científicos e didáticos - DBCA (Brasil, 2013) e foi aprovada pelo Comitê de Ética e Deontologia em Estudos e Pesquisas (CEDEP) da Universidade Federal do Vale do São Francisco (UNIVASF) com protocolo número 0025/190811.
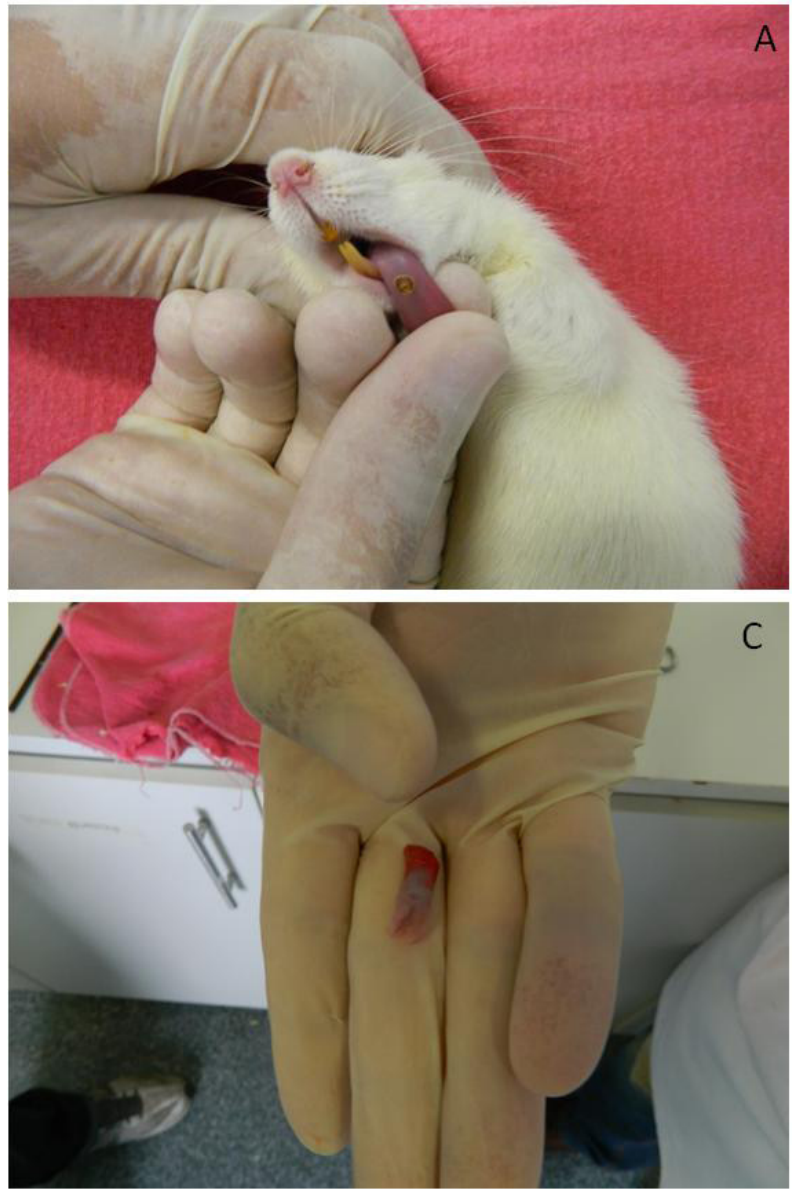

\section{RESULTADOS}

Com sete dias de experimentação, os aspectos macroscópicos das lesões nas línguas já começaram a apresentar diferenças visíveis, indicando os efeitos benéficos da ação local e sistêmica dos derivados dessa Punicaceae. Os animais do Grupo 2 apresentaram melhores resultados clínicos (Figura 2 ).

Com sete dias, no grupo controle (G4), os cortes apresentaram uma ulceração na mucosa com bordas afastadas, não houve danos na camada muscular. Foi observado tecido de granulação na região da lesão com intenso infiltrado inflamatório de polimorfonucleares e discretas áreas de edema. No grupo Polpa da romã (G1), houve persistência da ulceração, embora esta não atingisse a camada muscular. Houve início de reepitelização da lesão e subjacente a esta, observa-se um tecido reacional com intenso infiltrado inflamatório mononuclear, de permeio a uma exuberante rede vascular e alta atividade fibroblástica. No grupo Chá da casca
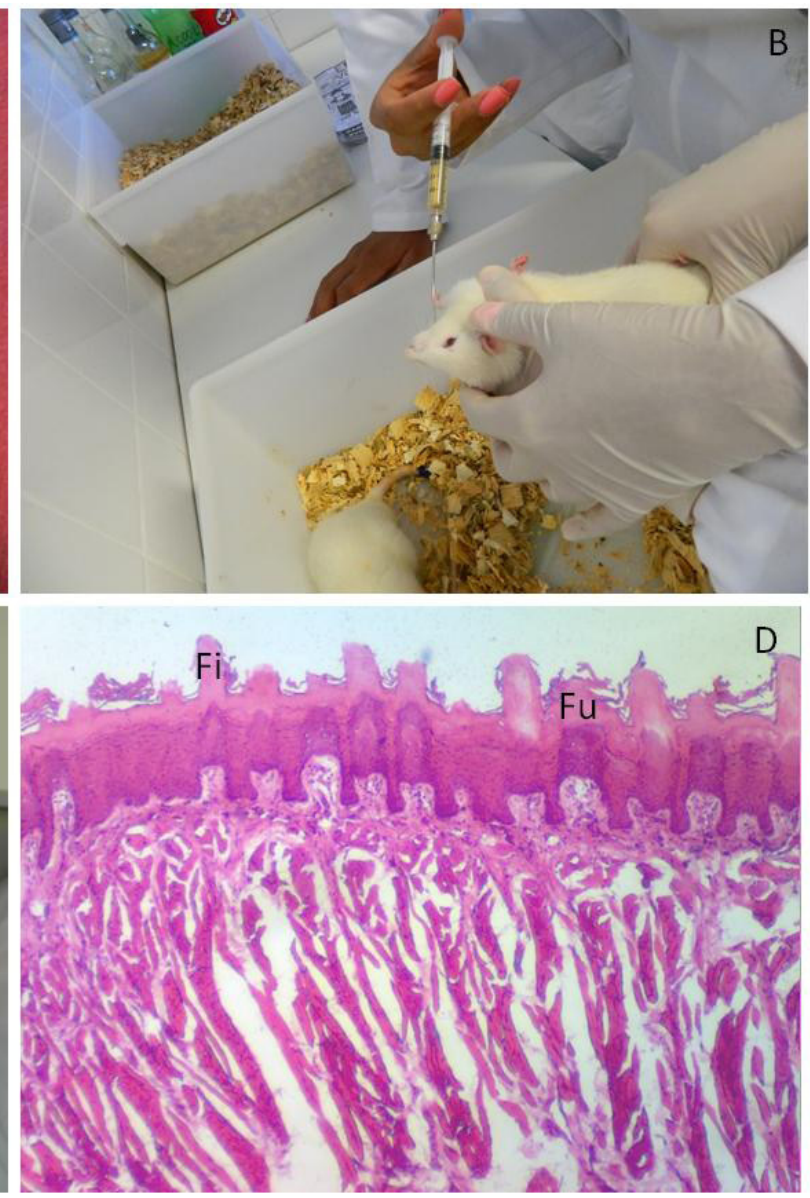

FIGURA 1. Metodologia usada no estudo da ação da romã (Punica granatum L.) na cicatrização de úlceras induzidas por queimadura em dorso de língua de ratos Wistar (Rattus norvegicus). A. Aplicação local da decocção da casca de romã. B. Aspecto do dorso de língua após a realização das queimaduras. C. remoção completa da língua para o histopatológico. D. Aspecto normal do dorso da língua com presença de papilas filiformes e fungiformes (HE, magnitude 10X). Fi = Papila Filiforme; Fu = Papila Fungiforme. 

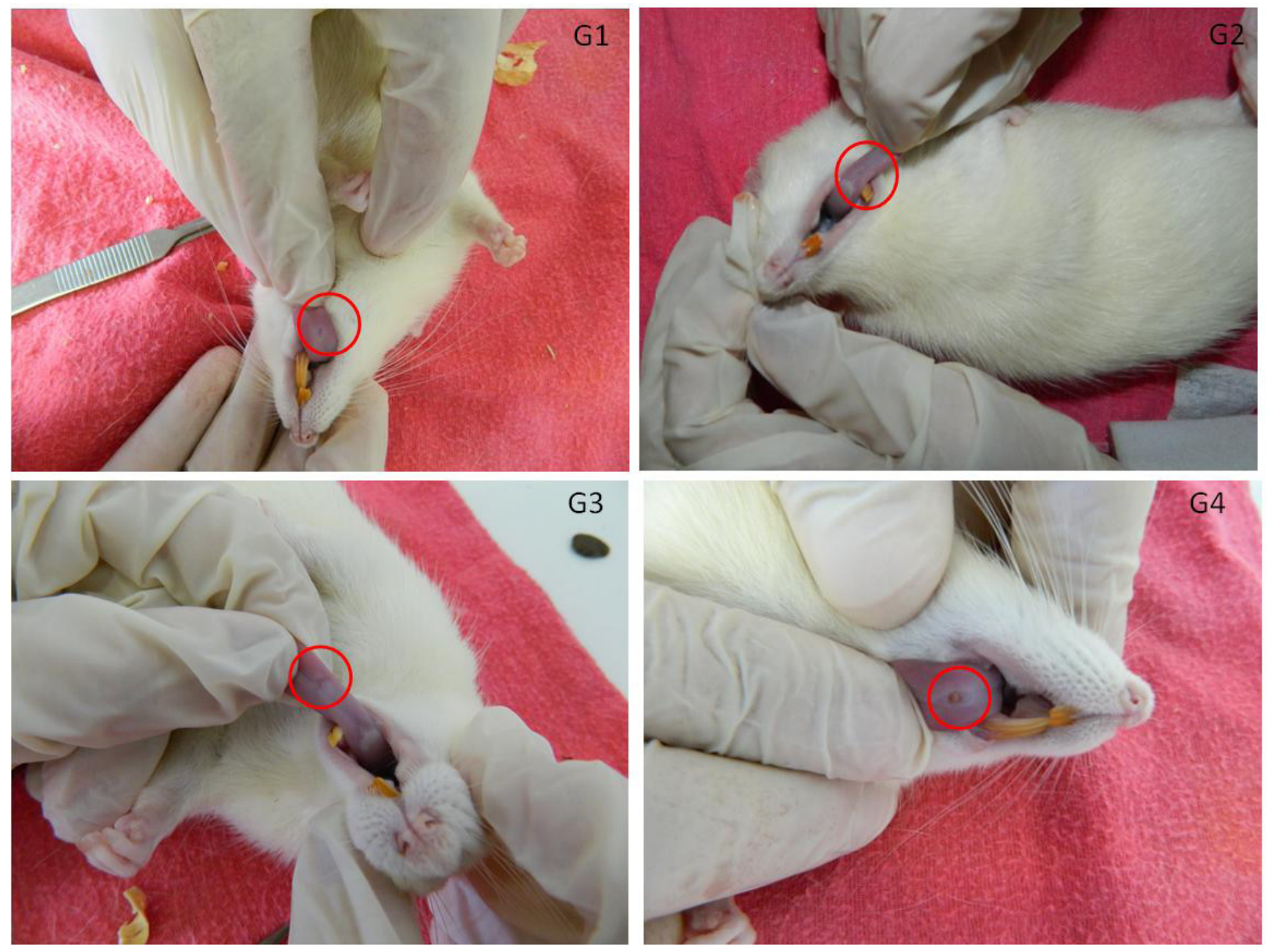

FIGURA 2. Aspecto macroscópico (clínicos) dos quatro grupos com sete dias de experimento. G1: Suco de romã; G2: Suco de romã + Aplicação local da decocção com casca da romã; G3: Aplicação local da decocção com casca da romã e G4: Controle negativo.

do fruto+ Polpa da romã (G2), a região da lesão mostrou reepitelização exibindo um epitélio bem diferenciado, embora não tenha apresentado papilas, queratinizado com número de camadas de células superior ao da região normal sugerindo hiperplasia e pequeno infiltrado inflamatório mononuclear. No grupo do Chá da casca do fruto (G3), os cortes apresentaram uma ulceração na mucosa, não houve danos na camada muscular. Foi observado tecido de granulação na região da lesão com intenso infiltrado inflamatório de polimorfonucleares e discretas áreas de edema. (Figura 3).

Com 14 dias, no grupo controle (G4), encontrou-se a presença de úlceras profundas sem cobertura tecidual, além de infiltrado inflamatório crônico. No grupo Polpa da romã (G1), a região da lesão mostrou reepitelização exibindo um epitélio bem diferenciado, embora não tenha apresentado papilas, queratinizado com número de camadas de células superior ao da região normal, sugerindo hiperplasia e áreas sugestivas de degeneração hidrópica. No grupo Chá da casca do fruto + Polpa da romã (G2), a região da lesão mostrou reepitelização exibindo um epitélio bem diferenciado, apresentando papilas, queratinizado com número de camadas normais e pequena área de fibrose. Observou-se maior semelhança com a mucosa normal (Figura 1D). O tecido conjuntivo subjacente apresentou grande número de fibroblastos cujos núcleos exibindo nucléolos evidentes indicaram intensa atividade metabólica no processo de reparo tecidual. No grupo do chá da casca do fruto (G3), a região da lesão exibiu um epitélio bem diferenciado, queratinizado, com número de camadas de células superior ao da região normal sugerindo hiperplasia e área sugestiva de acantose, sem a presença de papilas gustativas. (Figura 4).

Houve significância estatística $(p=0,026)$ quando se comparou o tratamento (Grupos G1, G2, G3 e G4) com os graus de reepitelização, indicando que no grupo $\mathrm{G} 2$, a reepitelização foi superior a dos outros grupos. Houve significância estatística $(p=0,023)$ quando se comparou o tratamento (Grupos G1, G2, G3 e G4) com os graus de inflamação, indicando que no grupo $\mathrm{G} 2$, o processo inflamatório foi resolvido mais rápido que nos outros grupos. Os piores escores obtidos foram atribuídos ao Grupo G4 no parâmetro grau de reepitelização e ao Grupo 

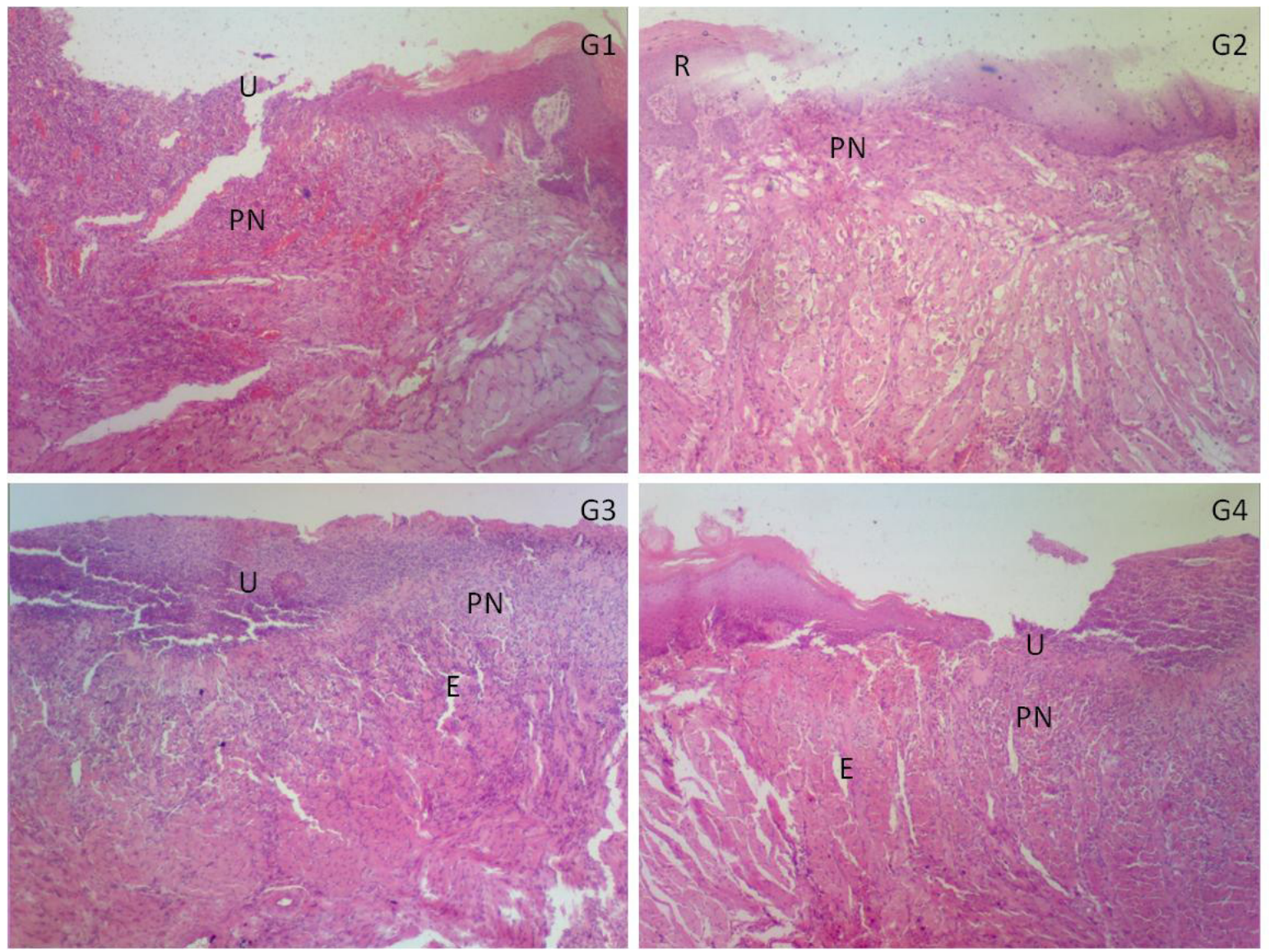

FIGURA 3. Aspecto histológico dos quatro grupos com sete dias de experimento. G1: Polpa de romã; G2: Polpa de romã + Chá da casca desidratada; G3: Chá da casca desidratada e G4: Controle negativo. U= Área Ulcerada; $\mathrm{R}=$ Reepitelização; $\mathrm{E}=\mathrm{Edema}$; $\mathrm{N}=$ infiltrado inflamatório de polimorfonucleares. (HE, magnitude10X).

G3 em relação ao grau de Inflamação (Tabela 1).

Observou-se que o grupo G2 apresentou cicatrização completa em 14 dias. O grupo controle (G4) no presente estudo apresentou a pior cicatrização (presença de úlceras). Os grupos G1 e G3 tiveram resultados semelhantes, com resultados melhores que no grupo G4 (Figura 4).

\section{DISCUSSÃO}

Não houve mortalidade de animais durante o experimento, nem perda de peso significante. No primeiro dia após as lesões nas línguas, os animais diminuíram o consumo de água e ração e apresentaram comportamento característico de dor como postura encurvada, piloereção, relutância em interagir, diminuição da excreção de urina e fezes, mas isso foi amenizado com a administração analgésico na água do bebedouro, acetominofenol na dosagem de $1 \mathrm{mg} / \mathrm{ml}$ por 24 horas (Damy et al., 2010).

Em relação ao tempo de cicatrização em epitélio, Murthy et al. (2004) verificaram o tempo de resolução de feridas em pele de ratos Wistar. $O$ grupo de ratos que recebeu o gel a $5 \%$ da casca de romã mostrou uma cura completa depois de 10 dias, enquanto os animais tratados com gel a 2,5 $\%$, a cura foi observada no dia 12 , em contraste com os animais do grupo controle que receberam o gel branco, o que levou 16-18 dias para a cura completa. Os autores concluíram que Punica granatum $L$. promove a cicatrização de feridas em ratos e uma avaliação mais aprofundada desta atividade em humanos é sugerida. No nosso estudo, as feridas no epitélio da língua cicatrizaram em 14 dias, já que a mucosa lingual sofre traumas durante a alimentação, isso pode justificar o tempo maior para resolução total das lesões.

A casca da romã também é rica em polifenóis, os quais têm apresentado um forte efeito antisséptico e também atividade antibacteriana contra gram-negativas e gram-positivas (Negi \& Jayaprakasha, 2003). Estes polifenóis presentes na casca podem ser responsáveis pela atividade de cicatrização de feridas (Murthy et al., 2004; Pirbalouti et al., 2010). Acredita-se que o efeito 

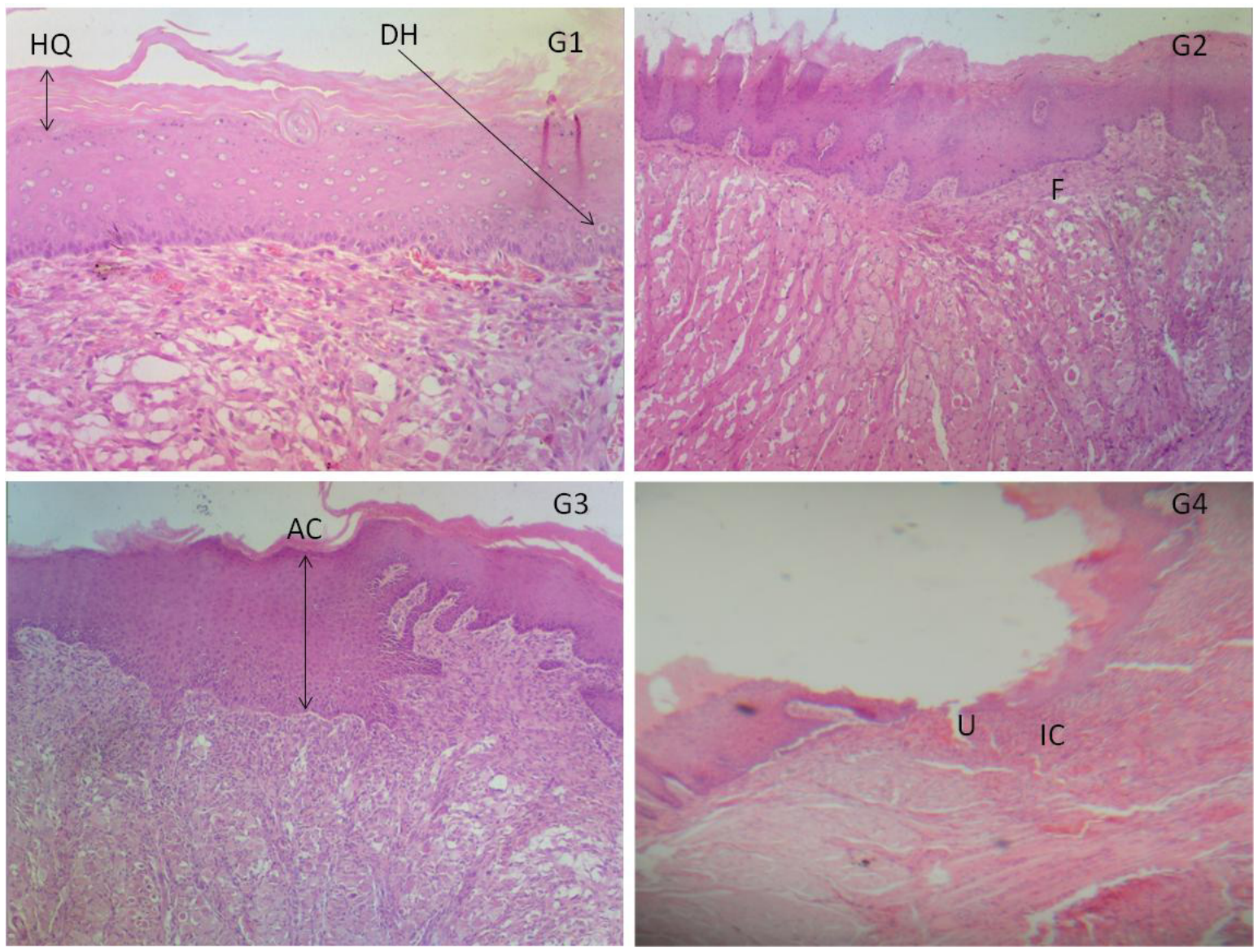

FIGURA 4. Aspecto histológico dos quatro grupos com 14 dias de experimento. G1: Polpa de romã; G2: Polpa de romã + Chá da casca desidratada; G3: Chá da casca desidratada e G4: Controle negativo. Aumento de 10x. $\mathrm{HQ}=$ Hiperqueratinização; $\mathrm{AC}=$ Acantose; $\mathrm{DH}=$ Degeneração Hidrópica; IC= Infiltrado Inflamatório Crônico; U= Área Ulcerada; F= Área de fibrose. (HE, magnitude 10X).

cicatricial do chá de romã no estudo está também associado à ação antifúngica e antibactericida dessa punicácea, que diminui a população de bactérias Gram positivas e Gram positivas do biofilme dental, diminuindo a translocação bacteriana para camada mais internas da mucosa (McCarrell et al., 2008; Gümüş et al., 2013). O extrato da casca de romã apresenta atividade antibacteriana contra $S$. aureus, S. epidermidis, L. acidophilus, S. mutans e S. salivarius que são encontradas na saliva e causam patologias nos tecidos duros e moles da cavidade bucal (Abdollahzadeh et al, 2011; Teles \& Costa, 2014).

A ação cicatrizante do suco pode estar associada à atividade antioxidante. No estudo de Husari et al. (2014), o suco de romã reduziu significativamente o estresse oxidativo, reduziu a inflamação, o edema e a infiltração de neutrófilos em hiperóxia. Além disso, reduziu significativamente a expressão de mediadores inflamatórios em ratos Wistar. No estudo de Parashar \& Badal (2011), o suco da romã se mostrou mais eficaz que o suco da laranja, porque além de vitamina $C$, esse suco contém Vitamina
$E$, que é poderosa para evitar danos oxidativos em seres humanos.

Com 14 dias, o grupo G4 apresentou presença de infiltrado inflamatório crônico e o grupo G2 não apresentou alterações inflamatórias importantes (Figura 3). Esse resultado foi diferente do encontrado por Sinha \& Gallagher (2003) que estudaram a cicatrização em língua por queimadura com bisturi elétrico. Esses autores não encontraram processo inflamatório em nenhum dos grupos de animais com 14 dias de experimentação. Em outro trabalho de cicatrização de queimaduras em ratos, realizado por Azadi et al. (2015), o grupo tratado não apresentou inflamação crônica e apresentou regeneração completa do epitélio em 14 dias.

Em relação à reepitelização em dorso de língua de ratos Wistar, Camacho-Alonso \& Lopez-Jornet (2007) observaram que com sete dias, o grupo tratado com o adesivo N-butil-2cianoacrilato, já apresentava reepitelização em $80 \%$ dos animais, embora de espessura irregular (grau 3). Em uma comparação com os outros grupos (Controle, ácido tricloroacético a 50\%, criocirurgia, 
TABELA 1. Avaliação qualitativa dos graus de Reepitelização e de Inflamação encontrados no estudo.

\begin{tabular}{|c|c|c|c|c|c|c|}
\hline Grupos & Animal & Dias & *Grau de Reepitelização & Média & ${ }^{* *}$ Grau de Inflamação & Média \\
\hline & R01 & 7 & 1 & & 2 & \\
\hline & R02 & 7 & 1 & & 1 & \\
\hline \multirow[t]{6}{*}{ G1 } & R03 & 7 & 0 & 1,16 & 2 & 2,16 \\
\hline & R04 & 14 & 2 & & 2 & \\
\hline & R05 & 14 & 2 & & 3 & \\
\hline & R06 & 14 & 1 & & 3 & \\
\hline & R07 & 7 & 3 & & 3 & \\
\hline & R08 & 7 & 3 & & 3 & \\
\hline \multirow[t]{6}{*}{ G2 } & R09 & 7 & 2 & 3,16 & 3 & 3,50 \\
\hline & R10 & 14 & 4 & & 4 & \\
\hline & R11 & 14 & 3 & & 4 & \\
\hline & R12 & 14 & 4 & & 4 & \\
\hline & R13 & 7 & 1 & & 1 & \\
\hline & R14 & 7 & 1 & & 1 & \\
\hline \multirow[t]{6}{*}{ G3 } & R15 & 7 & 1 & 1,67 & 1 & 1,83 \\
\hline & R16 & 14 & 2 & & 3 & \\
\hline & R17 & 14 & 2 & & 3 & \\
\hline & R18 & 14 & 3 & & 2 & \\
\hline & R19 & 7 & 0 & & 2 & \\
\hline & R20 & 7 & 0 & & 2 & \\
\hline \multirow[t]{4}{*}{ G4 } & R21 & 7 & 0 & 0,50 & 2 & 2,50 \\
\hline & R22 & 14 & 1 & & 3 & \\
\hline & R23 & 14 & 1 & & 3 & \\
\hline & R24 & 14 & 1 & & 3 & \\
\hline
\end{tabular}

Legenda: Os resultados mostraram significância estatística para os dois parâmetros avaliados com * $p=0,026 ;{ }^{* *} p=0,023$.

eletrocautério e laser de CO2), essa diferença foi estatisticamente significante. Aos 14 dias, as feridas foram totalmente reepitelizadas. No entanto, o grupo do adesivo mostrou o maior número de feridas de espessura regular (grau 4), mas não foi obtida diferença estatisticamente significativa entre os grupos. No nosso estudo, dois animais do grupo 2 já apresentaram grau 3 com sete dias de tratamento. Com 14 dias de experimentação, dois animais apresentaram grau 4 e um rato apresentou grau 3 (Tabela 1).

Em relação ao grau de inflamação em língua, no estudo de Sinha \& Gallagher (2003) todos os grupos apresentaram inflamação aguda com sete dias e aos 14 dias nenhum grupo apresentou inflamação crônica. No nosso estudo, o grupo 2 com sete dias, já apresentou $100 \%$ dos animais com grau 3 (Inflamação crônica, presença de células mononucleares). Com 14 dias, os três animais do grupo 2 apresentaram grau 4 . Todos os outros grupos apresentaram maiores graus de inflamação (Tabela 1). Isso pode indicar a eficácia do fitocomplexo contido no chá da casca do fruto combinado às substâncias encontradas na polpa.

\section{CONCLUSÃO}

Observou-se que os produtos da romã tiveram um efeito sinérgico (Local + Sistêmico), fato que contribuiu na cicatrização completa das úlceras de língua nos ratos do Grupo G2. Diante dos resultados, o chá da casca aplicado no local (bochechos) + a ingestão da polpa da Punica granatum L. se mostram eficazes no tratamento das afecções causadas nas línguas dos animais, e por isso, ratifica-se o uso concomitante dos dois derivados da romã na odontologia como coadjuvantes no tratamento clínico de úlceras bucais e aftas, por suas propriedades cicatrizantes observadas em mucosa de língua de ratos Wistar e confirmadas nesse estudo.

\section{REFERÊNCIAS}

ABDOLLAHZADEH, S.H.; et al. Antibacterial and antifungal activities of Punica granatum peel extracts 
against oral pathogens. Journal of Dentistry, v. 8, p. 1-6, 2011.

AFAQ, F.; et al. Anthocyanin and hydrolysable tanninrich pomegranate fruit extract modulates MAPK and NF-kB pathways and inhibits skin tumorigenesis in CD-1 mice. International Journal of Cancer, v. 113, p. 423-433, 2005.

AJAIKUMAR, K.B.; et al. The inhibition of gastric mucosal injury by Punica granatum L. (pomegranate) methanolic extract. Journal of Ethnopharmacology, v. 96, p. 171-176, 2005.

AZADI, M.; et al. Comparing the Effect of Visceral Fat and Barley Seed Ash (Hordeum Vulgare L) With Silversulfadiazine on Burn Wound Healing in Rats. Jundishapur Journal Natural Pharmaceutical Products. v. 10, n. 1, p. 1-6, 2015.

BRASIL. Ministério da Ciência, Tecnologia e Inovação. Conselho Nacional de Controle de Experimentação Animal - CONCEA. Diretriz Brasileira para o cuidado e a utilização de animais para fins científicos e didáticos - DBCA, 2013. Disponível em http://www.cobea.org.br/arquivo/download?ID_ $A R Q U I V O=20$. Data de acesso 20 de novembro de 2015.

CAMACHO-ALONSO. F.; LOPEZ-JORNET, P. Clinicalpathological study of the healing of wounds provoked on the dorso lingual mucosa in 186 albino rats. Otolaryngology-Head and Neck Surgery. v. 136, p. 119-124. 2007.

COSTA, G.B.F.; CASTRO, J.F.L. Etiologia e tratamento da estomatite aftosa recorrente - revisão de literatura, Medicina (Ribeirão Preto), v. 46, n. 1, p. 1-7, 2013.

DAMY, S.B.; et al. Aspectos fundamentais da experimentação animal - aplicações em cirurgia experimental. Revista da Associação Médica Brasileira, v. 56, n. 1, p.103-111, 2010.

FARIA, A.; CALHAU, C. The bioactivity of pomegranate: impact on health and disease. Critical Reviews in Food Science and Nutrition, v. 51, p. 626-634. 2011.

GÜMÜŞ. M.; et al. The effects of pomegranate on bacterial translocation in rats with obstructive jaundice. European Review for Medical and Pharmacological Sciences, v. 17, p. 1488-1494, 2013.

HELLO, M.; et al. Use of thalidomide for severe recurrent aphthous stomatitis: a multicenter cohort analysis. Medicine (Baltimore), v. 89, p. 176-82, 2010.

HOLETZ, F.B.; et al. Screening of some plants used in the Brazilian folk medicine for the treatment of infectious diseases. Memórias do Instituto Oswaldo Cruz, v. 97, p. 1027-1031, 2002.

HUSARI, A.; et al. Antioxidant activity of pomegranate juice reduces acute lung injury secondary to hyperoxia in an animal model. BMC Research Notes, v. 7, n. 664, p. 1-10, 2014.

JARDINI, F.A.; MANCINI FILHO, J. Avaliação da atividade antioxidante em diferentes extratos da polpa e sementes da romã (Punica granatum, L.). Revista Brasileira de Ciências Farmacêuticas, v. 43, n. 1, p. 137-147, 2007.

LUQUE-RODRIGUEZ, J. M.; et al. Dynamic superheated liquid extraction of anthocyanins and other phenolics from red grape skins of winemaking residues. Bioresource Technology, v. 98, n. 14, p. 27052713, 2007.

LANSKY, E.P.; NEWMANN, R.A. Punica granatum (pomegranate) and its potential for prevention and treatment of inflammation and cancer. Journal of Ethnopharmacology, v. 109, p. 177-206, 2007.

MCCARRELL, E.M.; et al. Antimicrobial activities of pomegranate rind extracts: enhancement by addition of metal salts and vitamin C, BMC Complementary and Alternative Medicine, v.15, n. 64, p. 1-7, 2008.

MESSADI, D.V.; YOUNAI, F. Aphthous ulcers. Dermatologic Therapy, v. 23, n. 3, p. 281-290, 2010.

MOHAN, M.; et al. Effect of pomegranate juice on Angiotensin II-induced hypertension in diabetic Wistar rats. Phytotherapy Research. v. 24, n. 2, p. 196-203, 2010.

MONEIM, A.E.A. Antioxidant activities of Punica granatum (pomegranate) peel extract on brain of rats. Journal of Medicinal Plants Research. v. 6, n. 2, p. 195-199, 2012.

MURTHY, K.N.C.; et al. Study on Wound Healing Activity of Punica granatum Peel. Journal of Medicinal Food, v. 7, n. 2, p. 256-259, 2004.

NEGI, P.S.; JAYAPRAKASHA, G.K. Antioxidant and antibacterial activities of Punica granatum peel extracts. Journal of Food Science, v. 68, n. 4, p. 1473-1477, 2003.

NEURATH, A.R.; et al. Punica granatum (pomegranate) juice provides an HIV-I entry inhibitor and candidate topical microbicide. BMC Infectious Diseases, v. 4, n. 41, p. 1-12, 2004.

NODA, Y.; et al. Antioxidant activities of pomegranate fruit extract and its anthocyanidins: delphinidin, cyaniding and pelargonidin. Journal of Agricultural and Food Chemistry, v. 50, n. 1, p. 166-171, 2002.

OLIVEIRA, L.P.; et al. Atividade citotóxica e antiangiogênica de Punica granatum L., Punicaceae. Revista brasileira de farmacognosia. v.20, n.2, p. 201-207, 2010.

PARASHAR, A.; BADAL, S. Pomegranate juice is potentially better than orange juice in improving antioxidant function in elderly subjects. Elixir Food Science Journal, v. 32, p. 2068-2074, 2011.

PIRBALOUTI, A.G.; et al. Wound Healing Activity of Malva Sylvestris and Punica Granatum in Alloxan-Induced Diabetic Rats. Acta Poloniae Pharmaceutica - Drug Research, v. 67, n. 5, p. 511-516, 2010.

REGEZI, J.A. Ulcerative conditions. In: REGEZI, J.A.; SCIUBBA, J.J.; JORDAN, R.C.K. Oral pathology: clinical pathologic correlations. Philadelphia: W.B. Saunders, p. 38-42, 2003.

RODRIGUES, E.R.; et al. Estudo de parâmetros bioquímicos em ratos sob ação de planta medicinal. XVI. Punica granatum L. Investigação - Revista Científica da Universidade de Franca (SP), v. 6, n. 1, p. 79-84, 2006.

ROSS, R.G.; et al. Imunomodulatory avtivity of Punica granatum in rabbits - a preliminary study. Journal of Ethnopharmacology, v. 78, n. 1, p. 85-87, 2001.

SEERAM, N.P.; et al. In vitro antiproliferative, apoptotic

Rev. Bras. PI. Med., Campinas, v.18, n.2, p.423-432, 2016. 
and antioxidant activities of punicalagin, ellagic acid and a total pomegranate tannin extract are enhanced in combination with other polyphenols as found inpomegranate juice. The Journal of Nutritional Biochemistry, v. 16, n. 6, p. 360-367, 2005.

SINHA, U.K.; GALLAGHER, L.A. Effects of steel scalpel, ultrasonic scalpel, $\mathrm{CO} 2$ laser, and monopolar and bipolar electro surgery on wound healing in guinea pig oral mucosa. The Laryngoscope. v. 113, p. 228-236, 2003.

SUMNER, M.D.; et al. Effects of pomegranate juice consumption on myocardial perfusion in patients with coronary heart diseases. American Journal of Cardiology, v. 96, n. 6, p. 810-814, 2005.

TELES, D.G.; COSTA, M.M. Estudo da ação antimicrobiana conjunta de extratos aquosos de Tansagem (Plantago major I., Plantaginaceae) e Romã (Punica granatum I., Punicaceae) e interferência dos mesmos na ação da amoxicilina in vitro. Revista Brasileira de Plantas Medicinais, v.16, n.2, p. 323-328, 2014. 